\title{
Existence and uniqueness for a quasilinear elliptic problem with nonlinear Robin conditions
}

\section{BITUIN CABARRUBIAS and PATRIZIA DONATO}

\section{ABSTRACT.}

This paper deals with an existence and uniqueness result of a weak solution for a quasilinear elliptic boundary value problem in a domain whose boundary is the union of two disjoint closed surfaces. On the interior boundary we prescribe a nonlinear Robin condition with suitable growth assumptions, and on the exterior boundary, a Dirichlet condition. The main difficulty when proving the existence of a solution is due to the nonlinear boundary condition, since, in order to apply a fixed point theorem, we need to prove the weak continuity of the associated boundary operator. To this aim, we first study several properties of this operator.

\author{
University OF THE PhiLIPPINES DiLIMAN \\ INSTITUTE OF MATHEMATICS \\ 1101 Diliman, QueZON CiTY \\ PHILIPPINES \\ E-mail address: bituin@math.upd.edu.ph \\ UNIVERSITY OF ROUEN \\ LABoratoire de Mathématiques RaphaËl SALEM \\ AVENUE DE L'UNIVERSITÉ, BP 12 \\ 76801 SAINT ETIENNE DE ROUVRAY, FRANCE \\ E-mail address: Patrizia.Donatoduniv-rouen.fr
}

